\title{
Ligustrazine ameliorates acute kidney injury through downregulation of NOD2-mediated inflammation
}

\author{
GUOSHENG JIANG $^{1 *}$, RUI XIN ${ }^{2 *}$, WENDAN YUAN $^{1 *}$, LIXIA ZHANG $^{1}$, XIANGHUI MENG $^{3}$, \\ WANGNAN SUN ${ }^{1}$, HUIRONG HAN ${ }^{4}$, YUN HOU ${ }^{1}$, LIN WANG $^{5}$ and PENGCHAO DU ${ }^{1}$ \\ ${ }^{1}$ School of Basic Medical Sciences, Binzhou Medical University, Yantai, Shandong 264003; \\ ${ }^{2}$ Center for Reproductive Medicine, National Research Center for Assisted Reproductive Technology and Reproductive Genetics, \\ Shandong University, The Key Laboratory of Reproductive Endocrinology, Shandong University, \\ Ministry of Education, Shandong Provincial Key Laboratory of Reproductive Medicine, Jinan, Shandong 250021; \\ ${ }^{3}$ Microwave Treatment Department, Central Hospital of Zibo (GaoQing Branch Courts), Zibo, Shandong 256300; \\ ${ }^{4}$ Department of Anesthesiology and Shandong Provincial Medicine and Health Key Laboratory of Clinical Anesthesia, \\ Weifang Medical University, Weifang, Shandong 261053; ${ }^{5}$ Department of Gerontology, \\ The Second Hospital of Shandong University, Jinan, Shandong 250000, P.R. China
}

Received July 16, 2019; Accepted November 25, 2019

DOI: $10.3892 /$ ijmm.2020.4464

\begin{abstract}
Ligustrazine has been used to alleviate clinical acute kidney injury (AKI); however, the underlying molecular mechanisms are poorly understood. In order to further elucidate the molecular mechanism underlying its occurrence, the role of nucleotide-binding oligomerization domain-containing 2 (NOD2) in AKI was investigated in the present study, and the results indicated that ligustrazine exerts an important protective effect against AKI in vivo by inhibiting the upregulation of NOD2 expression and reducing apoptosis of kidney cells following ischemia/reperfusion injury in rat models. Furthermore, the inhibitory role of ligustrazine on the upregulation of NOD2 and apoptosis of kidney cells induced
\end{abstract}

Correspondence to: Dr Pengchao Du, School of Basic Medical Sciences, Binzhou Medical University, 346 Guanhai Road, Yantai, Shandong 264003, P.R. China

E-mail: 252983491@qq.com

Abbreviations: AKI, acute kidney injury; NLRs, nucleotide-binding and oligomerization domain (NOD)-like receptors; I/R, ischemia/reperfusion; PRRs, pattern-recognition receptors; NOD2, nucleotide-binding oligomerization domain-containing 2; NLRP3, nucleotide-binding domain and leucine-rich repeat pyrin 3 domain; BDMCs, bone marrow-derived cells; $\mathrm{SCr}$, serum creatinine; BUN, blood urea nitrogen; TNF- $\alpha$, tumor necrosis factor- $\alpha$; IL-1 $\beta$, interleukin-1 $\beta$; MCP-1, monocyte chemoattractant protein-1; CQ, chloroquine; CCK-8, Cell Counting Kit-8; H\&E, hematoxylin and eosin

*Contributed equally

Key words: nucleotide-binding oligomerization domain-containing 2, autophagy, ligustrazine, inflammation, acute kidney injury by $\mathrm{CoCl}_{2}$ and oxygen and glucose deprivation followed by reoxygenation was investigated in in vitro experiments. The effect of ligustrazine on NOD2 downregulation was partially blocked by inhibiting autophagy. To the best of our knowledge, the results of the present study are the first to provide evidence that ligustrazine can inhibit NOD2-mediated inflammation to protect against renal injury, which may be in part attributed to the induction of autophagy. These findings may help design and develop new approaches and therapeutic strategies for AKI to prevent the deterioration of renal function.

\section{Introduction}

Acute kidney injury (AKI) is a complex pathophysiological process that is associated with the progression of chronic kidney disease. Previous studies have highlighted the role of the innate immune system and inflammatory mechanisms in the progression of AKI, particularly the activation of pattern-recognition receptors (PRRs) $(1,2)$. Nucleotide-binding and oligomerization domain (NOD)-like receptors (NLRs), which are members of the family of PRRs, are known to be involved in kidney ischemia/reperfusion (I/R) injury $(3,4)$, and may represent a potential therapeutic target to abrogate the pathogenesis of AKI. Among the known NLRs, nucleotide-binding oligomerization domain-containing 2 (NOD2) and nucleotide-binding domain and leucine-rich repeat pyrin 3 domain (NLRP3) act as sensors of 'cellular danger' (5), and belong to two different subfamilies based on the nature of their N-terminal domains. These proteins play a key role in the control of inflammatory and immune responses through the modulation of different signaling pathways, including those dependent on nuclear factor $(\mathrm{NF})-\kappa \mathrm{B}$ and the caspase-1-mediated cleavage of interleukin (IL)-1 $\beta$ and IL-18, respectively $(6,7)$. Moreover, NOD2 and NLRP3 are extensively involved in the progression of renal diseases (8-12). Suppression of NOD2-mediated immune responses was found to attenuate hypoxia-induced 
inflammatory effects and apoptosis in proximal tubule epithelial cells (13), and knockout of NLRP3 was shown to inhibit the activation of bone marrow-derived cells and $\mathrm{T}$ cells in a mouse IgA nephropathy model (10). Therefore, preventing inflammation mediated by the activation of NLRs may be considered as a potential therapeutic option for AKI.

Ligustrazine is a bioactive alkaloid that is extracted from the Chinese herb Ligusticum wallichii Franchat, which has long been used for the treatment of cardiac and cerebral diseases (14). As a calcium antagonist and reactive oxygen species scavenger, ligustrazine can significantly improve cardiac and cerebral blood flow $(15,16)$. It may also be used to alleviate clinical renal injury following AKI. However, the mechanisms underlying its protective effects remain poorly understood. The anti-inflammatory effect of ligustrazine was recently demonstrated in patients with rheumatic heart disease, an allergic asthma mouse model, and a rat model of spinal cord I/R injury (17-19), suggesting that this effect may represent the mechanism through which this compound confers renal protection. The aim of the present study was to investigate whether ligustrazine can inhibit NOD2-mediated inflammation.

\section{Materials and methods}

Animal studies. A total of 27 male Sprague-Dawley rats, aged 8 weeks and weighing 280-300 g, were purchased from the Laboratory Animals Center of Shandong University. The animals were housed in standard cages and maintained under standard conditions at a constant room temperature of $20-25^{\circ} \mathrm{C}$, a humidity of $40-70 \%$ and a $12 / 12 \mathrm{~h}$ light/dark cycle, with unrestricted access to food and water. The methods for generating a kidney I/R injury model were as follows: The rats were anesthetized via intraperitoneal injection of pentobarbital sodium ( $50 \mathrm{mg} / \mathrm{kg}$ body weight). Subsequently, the left renal artery and vein were exposed via an abdominal midline incision and separated. Ischemia of the left kidney was induced by occluding the artery with non-traumatic microvascular clamps. The right renal artery was immediately separated from the branch originating from the abdominal aorta and occluded by non-traumatic microvascular clamps. The kidney color then changed from red to black-red on visual inspection, which indicated that the cessation of blood flow was successful. At $50 \mathrm{~min}$ after induction of ischemia, the clamps were removed and the color of the kidneys returned to red, indicating reperfusion. The incisions were sutured, followed by the injection of penicillin and saline (30 $\mu \mathrm{l} / \mathrm{g}$ body weight) to replenish fluid loss. Reperfusion lasted for $24 \mathrm{~h}$. The rats were allowed to recover from anesthesia between I/R and the endpoint of the experiment $24 \mathrm{~h}$ later. Ligustrazine-treated rats were administered ligustrazine hydrochloride $(40 \mathrm{mg} / \mathrm{kg}$ body weight; Harbin Medisan Pharmaceutical, Co., Ltd.) via intraperitoneal injection once every $6 \mathrm{~h}$ during the reperfusion period (20-22). During surgery, all rats were placed on a homeothermic pad to maintain body temperature at $37^{\circ} \mathrm{C}$, and wet warm gauze was used to cover the incision to keep the tissue moist. After $24 \mathrm{~h}$ of reperfusion, the rats were anesthetized by intraperitoneal injection of $50 \mathrm{mg} / \mathrm{kg}$ pentobarbital sodium, and then rapidly sacrificed using $\mathrm{CO}_{2}$ asphyxiation, with a fill rate of $20 \%$ of the chamber volume/min. Death was confirmed using a combination of criteria, including lack of pulse, breathing, corneal reflex, response to a firm toe pinch and graying of the mucous membranes, which conformed to the AVMA Guidelines for the Euthanasia of Animals: 2013 Edition (23). Plasma and tissue samples were collected and stored at $-80^{\circ} \mathrm{C}$ or fixed in $4 \%$ formaldehyde at $4^{\circ} \mathrm{C}$ for $24 \mathrm{~h}$ for analysis.

Assessment of renal function. Blood from the heart was collected into homemade anticoagulant tubes with $3.8 \%$ sodium citrate, and serum was isolated by centrifugation at $3,000 \mathrm{x} \mathrm{g}$ for $10 \mathrm{~min}$ at $4^{\circ} \mathrm{C}$. Serum creatinine (SCr) and blood urea nitrogen (BUN) were measured using creatinine assay kits and urea assay kits in accordance with the manufacturer's instructions (Nanjing Jiancheng Bioengineering Institute).

Histological assessment. Formalin-fixed kidneys were embedded in paraffin, and $4-\mu \mathrm{m}$ sections were stained with hematoxylin for $5 \mathrm{~min}$ and eosin for 1-3 $\mathrm{min}$ at room temperature $\left(25^{\circ} \mathrm{C}\right)$. Histological scoring was conducted in a blinded manner. The percent injury in tubules of the outer medulla based on cell blebbing or vacuolization and/or necrosis was scored as follows: 0 (none); 1 (0-10\%); 2 (11-25\%); 3 (26-45\%); $4(46-75 \%)$; or $5(>75 \%)$. A total of 10 high-power fields (magnification, $\mathrm{x} 200$ ) per section were examined by Leica DM 6000 B light microscope (Leica Microsystems GmbH).

Immunohistochemical examination. Paraffin-embedded renal tissue sections were used for immunohistochemistry and the samples were examined using a Leica DM 6000 B light microscope (Leica Microsystems $\mathrm{GmbH}$ ). The sections were incubated with primary polyclonal antibodies against NOD2 (cat. no. ab197030, 1:200, Abcam) and caspase 3/cleaved caspase 3 (cat. no. WL02117, 1:100, Wanleibio Co., Ltd.) at $4^{\circ} \mathrm{C}$ overnight. Subsequently, the sections were incubated with the secondary HRP-goat anti-rabbit IgG antibodies for $30 \mathrm{~min}$ at room temperature $\left(25^{\circ} \mathrm{C}\right)$ according to the rabbit polymer detection system (PV-6001; ZSGB-BIO).

$R N A$ extraction and reverse transcription quantitative $P C R(R T-q P C R)$ analysis. Total RNA was isolated from the kidney using TRNzol reagent (Tiangen Biotech Co., Ltd.) and converted to complementary DNA by RT kit (Tiangen Biotech Co., Ltd.) at $70^{\circ} \mathrm{C}$ for $5 \mathrm{~min}, 37^{\circ} \mathrm{C}$ for $5 \mathrm{~min}, 42^{\circ} \mathrm{C}$ for $60 \mathrm{~min}$ and $70^{\circ} \mathrm{C}$ for $10 \mathrm{~min}$. qPCR reactions $(20 \mu \mathrm{l})$ were performed with SYBR ${ }^{\circledR}$ Premix Ex Taq ${ }^{\mathrm{TM}}$ (Takara Bio Inc.), and the thermocycling conditions were as follows: $94^{\circ} \mathrm{C}$ for $5 \mathrm{~min}$, $95^{\circ} \mathrm{C}$ for $30 \mathrm{sec}$, followed by 40 cycles at $59^{\circ} \mathrm{C}$ for $30 \mathrm{sec}, 72^{\circ} \mathrm{C}$ for $30 \mathrm{sec}, 72^{\circ} \mathrm{C}$ for $10 \mathrm{~min}$ and $65-95^{\circ} \mathrm{C}$ for $15 \mathrm{~min}$. Bio-Rad iCycler system software, version 3.1 (Bio-Rad Laboratories, Inc.) was used for quantitative data analysis. The specific primers were as follows: Forward, 5'-TACCTGAGAAAG CACCACCG-3' and reverse, 5'-GCACTGACAGCCAAGTAG AACG-3' for NOD2; and forward, 5'-TGCATCCTGCACCAC CAACTGC-3' and reverse, 5'-ACAGCCTTGGCAGCACCAG TGG-3' for the housekeeping gene GAPDH. The $2^{-\Delta \Delta C q}$ method was used to calculate the relative mRNA expression (24).

Cell culture and treatments. Rat proximal tubule epithelial cells (NRK-52E cells, Falcon, BD Biosciences) were cultured in serum-free Dulbecco's modified Eagle's medium (HyClone; 
Table I. Physical and biochemical parameters of experimental animals.

\begin{tabular}{lccc}
\hline Variables & Sham & I/R & I/R + Ligu \\
\hline Body weight $(\mathrm{g})$ & $222 \pm 18$ & $220 \pm 20$ & $223 \pm 15$ \\
Blood urea nitrogen $(\mathrm{mmol} / \mathrm{l})$ & $8.9 \pm 0.93$ & $42.1 \pm 4.57^{\mathrm{a}}$ & $22.7 \pm 0.85^{\mathrm{b}}$ \\
Serum creatinine $(\mu \mathrm{mol} / \mathrm{l})$ & $69.8 \pm 10.26$ & $206.1 \pm 25.73^{\mathrm{a}}$ & $145.6 \pm 15.49^{\mathrm{b}}$ \\
$\mathrm{N}$ & 9 & 9 & 9 \\
\hline
\end{tabular}

Values are expressed as mean \pm standard error of the mean. ${ }^{\mathrm{a}} \mathrm{P}<0.05 \mathrm{vs}$. scramble rats, was considered statistically significant. ${ }^{\mathrm{b}} \mathrm{P}<0.05 \mathrm{vs}$. I/R rats, was considered statistically significant. Sham, scramble rats; I/R, renal ischemia/reperfusion rats; I/R + Ligu, renal ischemia/reperfusion rats receiving ligustrazine treatment.

GE Healthcare Life Sciences) at pH 7.4 and $37^{\circ} \mathrm{C}$ with $5 \% \mathrm{CO}_{2}$. The medium was changed $2 \mathrm{~h}$ before all the experiments were performed.

In vitro experiments were performed using two models to mimic hypoxic conditions. The first model included incubating NRK-52E cells with different concentrations of $\mathrm{CoCl}_{2}(0,100$, 250 and $500 \mu \mathrm{M}$ ) for $12 \mathrm{~h}$ (anoxia) (13). The second model involved oxygen and glucose deprivation (OGD) followed by reoxygenation, in which NRK-52E cells were incubated in a hypoxic environment for $2 \mathrm{~h}\left(1 \% \mathrm{O}_{2}\right.$ and glucose-free buffer), which was followed by reoxygenation for $24 \mathrm{~h}$. Subsequently, in vitro reperfusion was achieved by incubating cells in normal medium for $24 \mathrm{~h}$ (recovery); ligustrazine (30 and $50 \mu \mathrm{M}$ ) was added immediately after reperfusion in routine culture medium for $24 \mathrm{~h}$. Chloroquine (CQ; Sigma-Aldrich; Merck $\mathrm{KGaA}$ ), an autophagy inhibitor, was also added at a concentration of $50 \mu \mathrm{M}$ immediately after reperfusion in routine culture medium for $24 \mathrm{~h}$.

Western blot analysis. Renal cortical tissues and cultured cells were homogenized in ice-cold RIPA lysis buffer with $1 \mathrm{mM}$ phenylmethanesulfonyl fluoride (Beyotime Institute of Biotechnology). Protein quantification was determined by Enhanced BCA Protein Assay kit (P0006, Beyotime Institute of Biotechnology). Equal amounts of protein extract $(40 \mu \mathrm{g})$ were loaded per lane and separated by $8-12 \%$ sodium dodecyl sulfate polyacrylamide gel electrophoresis and transferred to polyvinylidene fluoride membranes (EMD Millipore). Non-specific binding was blocked by incubation with $5 \%$ skimmed milk for $15 \mathrm{~min}$ at room temperature. The membranes were incubated with the indicated primary antibodies at $4^{\circ} \mathrm{C}$ overnight and subsequently hybridized with horseradish peroxidase-conjugated secondary antibodies (ProteinTech Group, Inc.) for $1 \mathrm{~h}$ at room temperature. The bands were visualized using Millipore Immobilon ECL (EMD Millipore). Primary antibodies included those against NOD2 (cat. no. ab197030, 1:1,000, Abcam), LC3A/B (cat. no. 4108, 1:1,000, Cell Signaling Technology, Inc.), CD68 (cat. no. wl01218, 1:100, Wanleibio Co., Ltd.) and $\beta$-actin (cat. no. 60008-1-Ig, 1:5,000, ProteinTech Group, Inc.). The second antibodies included HRP-conjugated Affinipure Goat Anti-Mouse IgG (H + L) (cat. no. SA00001-1, 1:3,000, ProteinTech Group, Inc.) and HRP-conjugated Affinipure Goat Anti-Rabbit IgG (H + L) (cat. no. SA00001-2, 1:3,000, ProteinTech Group, Inc.).
Detection of cytokines and chemokines. Chemokines and cytokines in the kidney and cells were measured using rat TNF- $\alpha$, IL-6 and MCP-1 ELISA kits (RTA00, R6000B and DY3144-05, respectively; R\&D Systems, Inc.) according to the procedure recommended by the manufacturer. The samples were read at $450 \mathrm{~nm}$ within $30 \mathrm{~min}$ by Spectramax Microplate Reader (Molecular Devices, LLC).

TUNEL assays. TUNEL assays were performed according to the manufacturer's instructions (Roche Diagnostics) to detect cell death in the kidney following I/R injury and ligustrazine administration, and in NRK-52E cells in response to different treatments. Samples were visualized using the Leica TCS SPE confocal system (Leica Microsystems $\mathrm{GmbH}$ ).

Cell viability. Cell Counting Kit-8 (CCK-8) assays (Beyotime Institute of Biotechnology) were performed according to the manufacturer's instructions. NRK-52E cells were plated in 96-well plates and subjected to different treatments. CCK-8 reagents were added and the cells were incubated in a cell incubator at $37^{\circ} \mathrm{C}$ for $4 \mathrm{~h}$. The absorbance was measured at $450 \mathrm{~nm}$ using the Infinite ${ }^{\circledR} 200$ PRO multimode microplate reader (M200 Pro/F200 Pro, Tecan Group, Ltd.).

Statistical analyses. Data are expressed as means \pm standard error of the mean. The significance of the differences in mean values among groups was examined by two-way ANOVA followed by Bonferroni post hoc tests when $>1$ variables were compared, and others were performed by one-way ANOVA followed by Duncan's multiple range tests. SPSS software, version 17.0 (SPSS, Inc.) and GraphPad Prism 5 software (GraphPad Software, Inc.) were used for statistical analyses. $\mathrm{P}<0.05$ was considered to indicate statistically significant differences.

\section{Results}

Ligustrazine protects against AKI by suppressing tubular damage and inflammatory response following $I / R$ in a rat model. Compared with the sham-operated group, I/R resulted in higher levels of SCr and BUN in rats, which was reduced by ligustrazine treatment (Table I). Histological examination following H\&E staining revealed severe morphological kidney injury, with scattered single cell necrosis or desquamation of proximal tubular cells with intact basement membranes, loss 
A
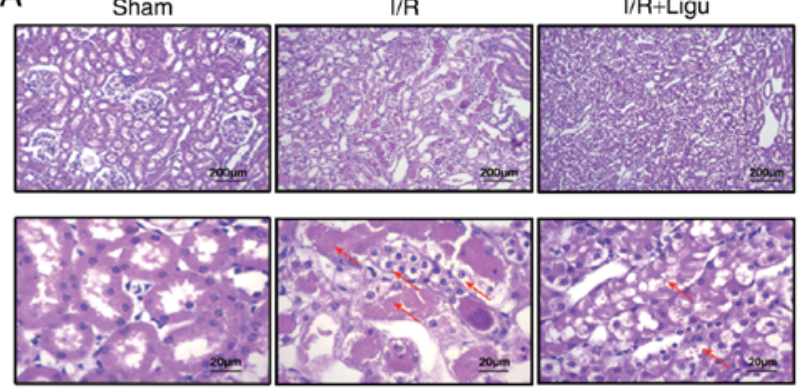

C

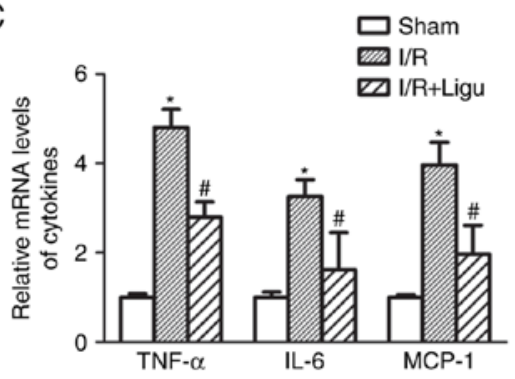

$E$

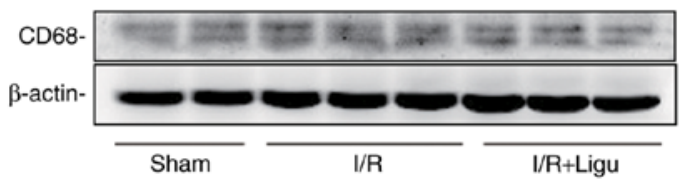

B
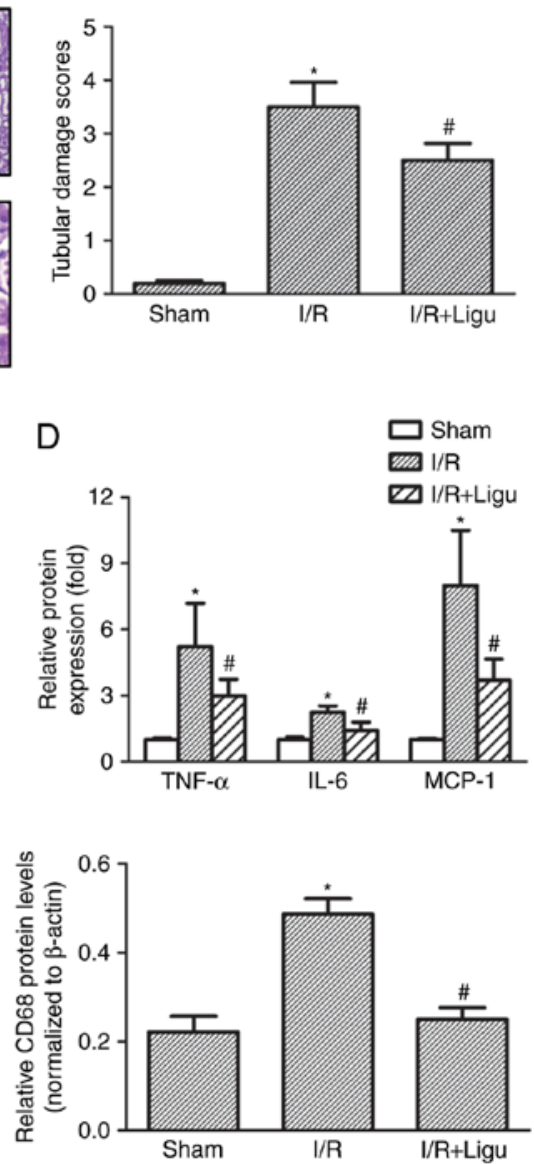

$\mathrm{F}$
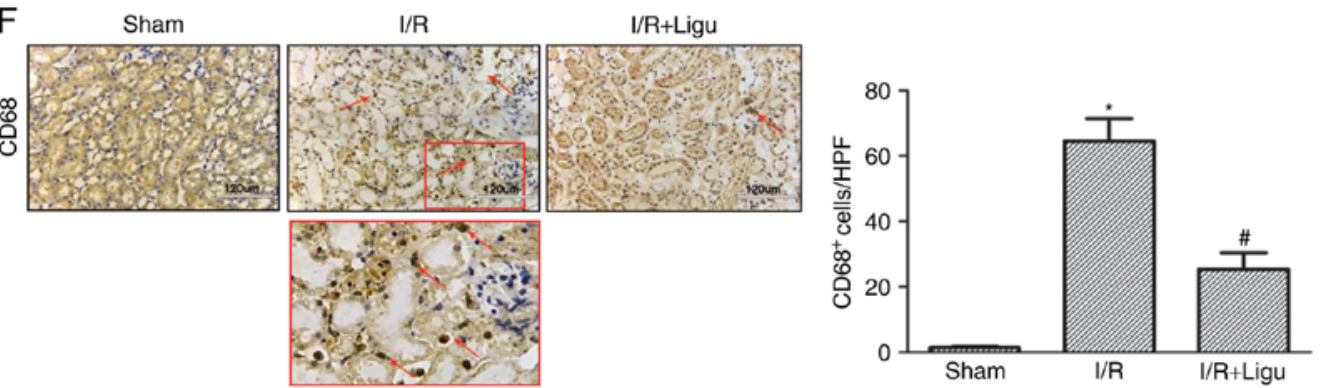

Figure 1. Ligustrazine protects against AKI by suppressing tubular damage and inflammatory responses following I/R in a rat model. (A) Representative photomicrographs showing the morphological changes of kidneys from different groups of rats. Red arrows indicated morphological kidney injury with scattered single cell necrosis or desquamation of proximal tubular cells with intact basement membranes, loss of the brush border and tubule dilation. Bars, $200 \mu \mathrm{m}$ at lower magnification (x40). Bars, $20 \mu \mathrm{m}$ at higher magnification (x400). (B) Quantitative assessment of tubular damage from different groups of rats (C) RT-qPCR analysis showing the levels of proinflammatory mediators (TNF- $\alpha$, IL-6 and MCP-1) in different groups of rats. (D) ELISA was used to evaluate the levels of proinflammatory mediators in different groups of rats. (E) Representative western blots and summarized data showing the protein levels of CD68 in kidneys from different groups. (F) Representative photomicrographs of CD68 IHC staining in kidneys from different groups. Bars, $120 \mu \mathrm{m}$ (magnification, $\mathrm{x} 200) .{ }^{*} \mathrm{P}<0.05$ vs. sham-operated rats $(\mathrm{n}=9),{ }^{\#} \mathrm{P}<0.05$ vs. I/R rats $(\mathrm{n}=9)$. Ligu, ligustrazine; AKI, acute kidney injury; I/R, ischemia/reperfusion; RT-qPCR, reverse transcription-quantitative PCR; TNF, tumor necrosis factor; IL, interleukin; MCP, monocyte chemoattractant protein.

of the brush border and tubule dilatation subsequent to $\mathrm{I} / \mathrm{R}$ injury, which were alleviated in the ligustrazine treatment group (Fig. 1A and B). Ligustrazine was also found to reduce the levels of pro-inflammatory mediators, including tumor necrosis factor (TNF)- $\alpha$, IL- 6 and monocyte chemoattractant protein (MCP)-1, in renal tissue after I/R injury, based on RT-qPCR analysis (Fig. 1C and D). Furthermore, western blot analysis demonstrated that the protein levels of CD68 were also suppressed by ligustrazine (Fig. 1E), and the number of infiltrating $\mathrm{CD} 68^{+}$macrophages was also decreased in the ligustrazine treatment groups (Fig. 1F). Therefore, the downregulation of the aforementioned cytokines and CD68 ${ }^{+}$ macrophages indicated that ligustrazine may protect against AKI by suppressing tubular damage and inflammatory response after $\mathrm{I} / \mathrm{R}$ in a rat model.

Ligustrazine inhibits the upregulation of NOD2 following $I / R$. RT-qPCR (Fig. 2A) and western blot (Fig. 2B) analyses demonstrated that the upregulation of NOD2 expression following I/R injury was inhibited by ligustrazine treatment at both the mRNA and protein levels, respectively. Immunohistochemical staining also identified high expression of NOD2 in the 
A

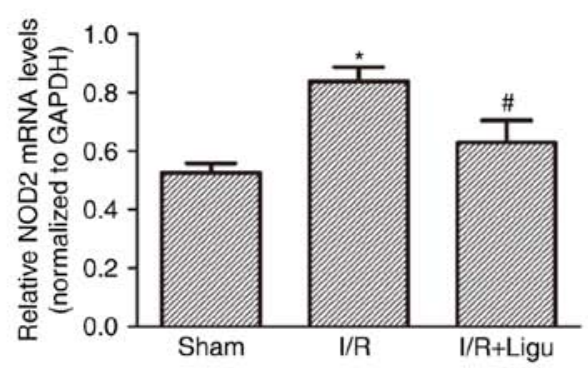

B

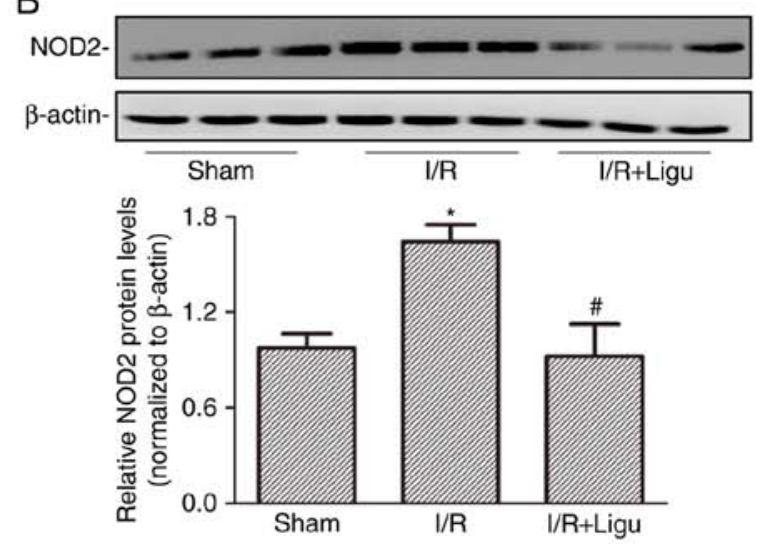

C
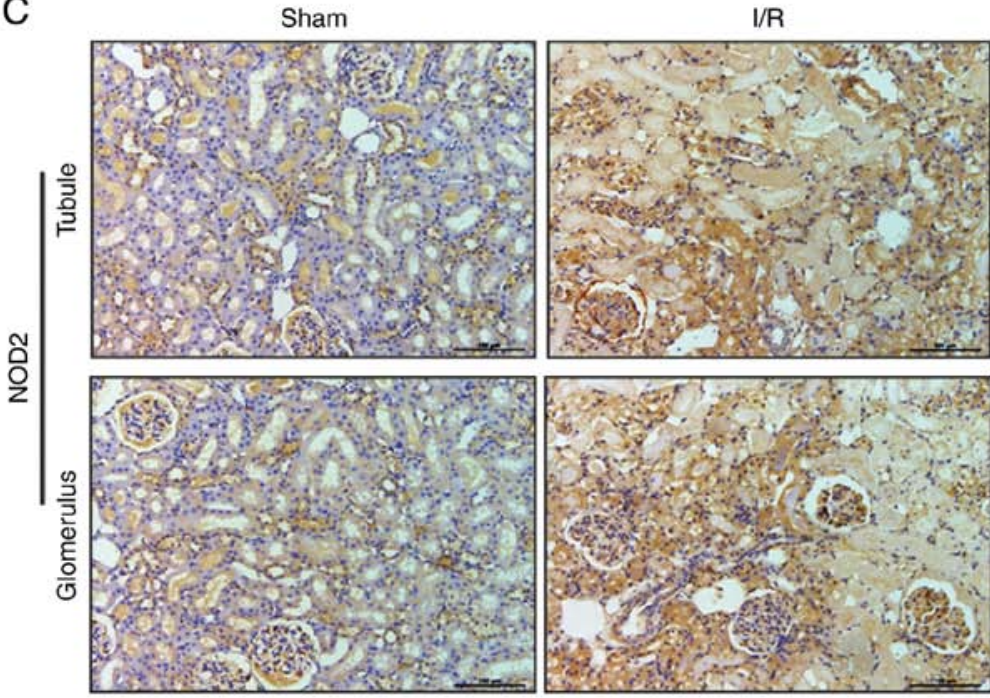

I/R+Ligu

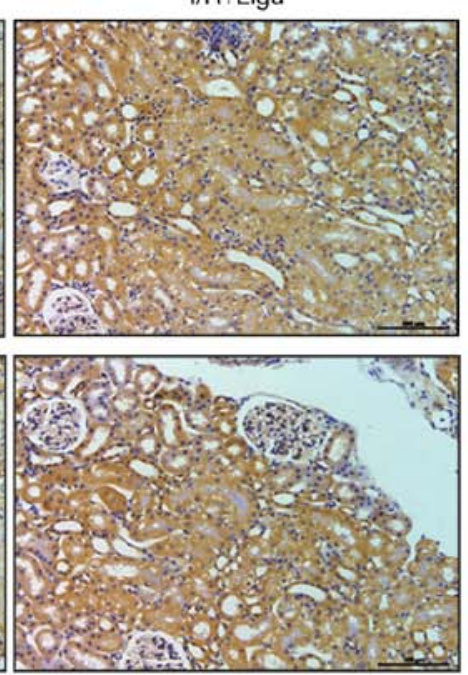

D
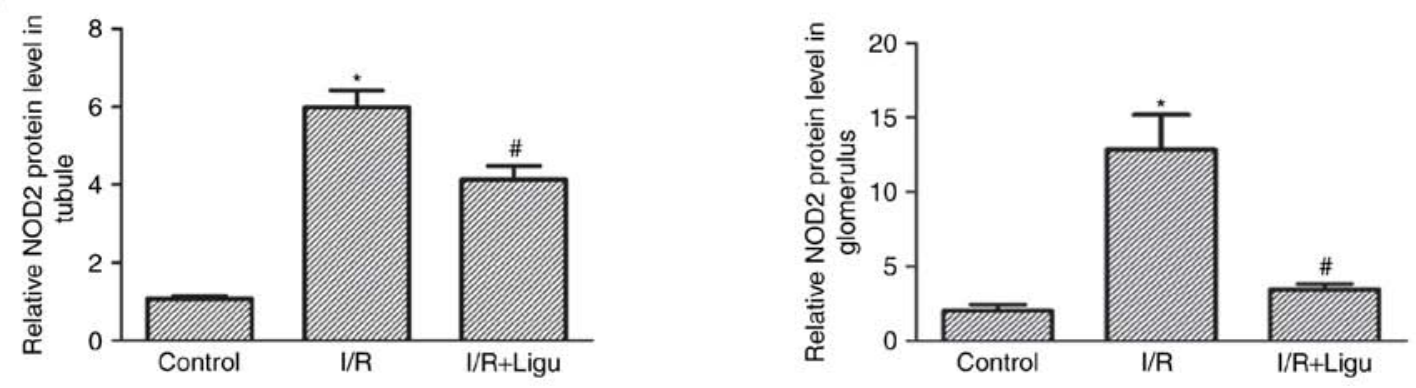

Figure 2. Ligustrazine inhibits the upregulation of NOD2 following I/R in a rat model. (A) Relative quantitation of mRNA levels of NOD2 by RT-qPCR analysis in kidneys from different groups. (B) Representative western blots and summarized data showing the protein levels of NOD2 in kidneys from different groups. (C) Representative photomicrographs of NOD2 IHC staining in the tubules and glomeruli of kidneys from different groups. Bars, $100 \mu \mathrm{m}$ (magnification, $\mathrm{x} 200$ ). (D) Quantitative analysis of IHC staining showing increased expression of NOD2 in the tubules and glomeruli of rats after I/R, which was significantly decreased with ligustrazine administration. ${ }^{~} \mathrm{P}<0.05$ vs. sham-operated rats $(\mathrm{n}=9),{ }^{\mathrm{H}} \mathrm{P}<0.05$ vs. I/R rats $(\mathrm{n}=9)$. Ligu, ligustrazine; I/R, ischemia/reperfusion; NOD2, nucleotide-binding oligomerization domain-containing 2; IHC, immunohistochemistry.

tubules and glomerulus following I/R, which was inhibited by ligustrazine treatment (Fig. 2C and D).

Ligustrazine inhibits apoptosis of kidney cells following I/R. Ligustrazine reduced cell death, as demonstrated by TUNEL staining and analysis (Fig. 3A). The inhibition of apoptosis by ligustrazine was further confirmed by caspase 3/cleaved caspase 3 immunohistochemistry (Fig. 3B) and western blotting (Fig. 3C). These results collectively indicated that ligustrazine exerted a renoprotective effect by reducing apoptosis of kidney cells and promoting renal function following I/R injury.
Ligustrazine suppresses NOD2 expression induced by $\mathrm{CoCl}_{2}$ or hypoxia in rat NRK-52E cells. Proximal tubule injury is prominent during AKI; therefore, rat proximal tubule epithelial cells (NRK-52E cells) were treated with $\mathrm{CoCl}_{2}$ and OGD to model the effect of AKI induced by hypoxia in vitro. The upregulation of NOD2 expression with different concentrations of $\mathrm{CoCl}_{2}$ was demonstrated by western blot analysis (Fig. 4A). The expression of NOD2 was shown to increase after OGD treatment followed by reoxygenation for $24 \mathrm{~h}$ (Fig. 4B). The effect of ligustrazine on the upregulation of NOD2 expression was then detected in both in vitro models in NRK-52E cells. 
A
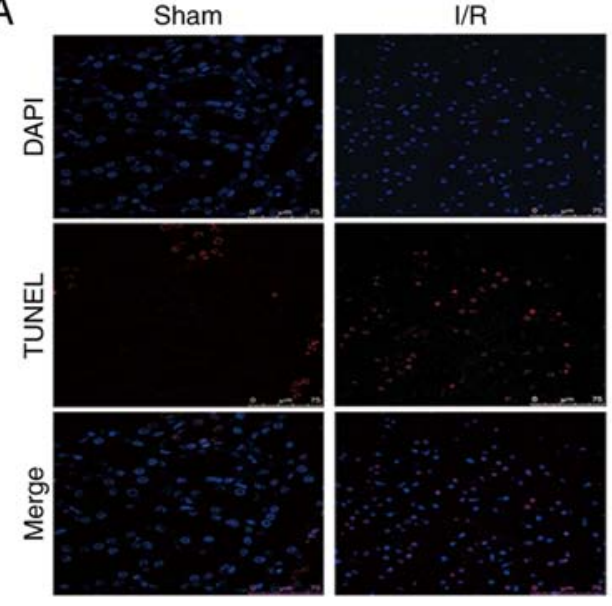

B
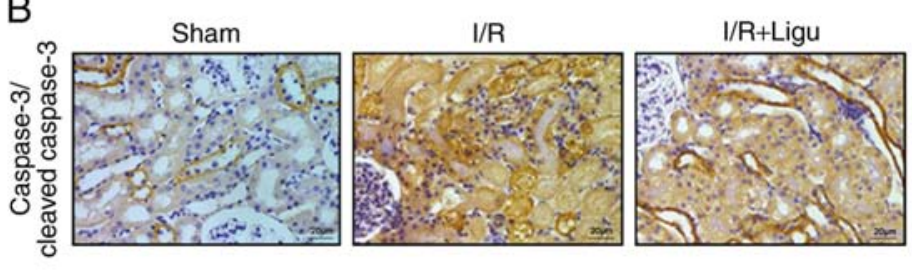

C

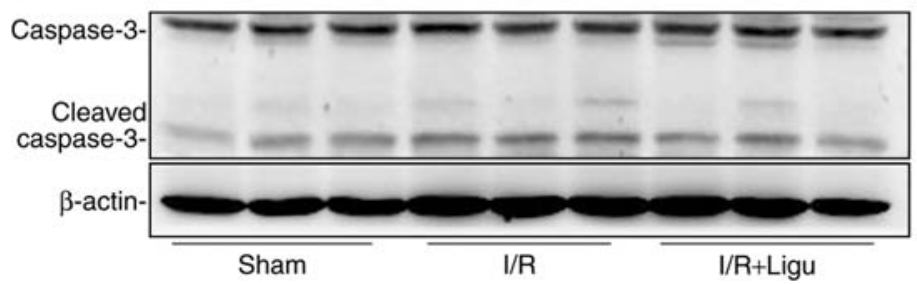

l/R+Ligu
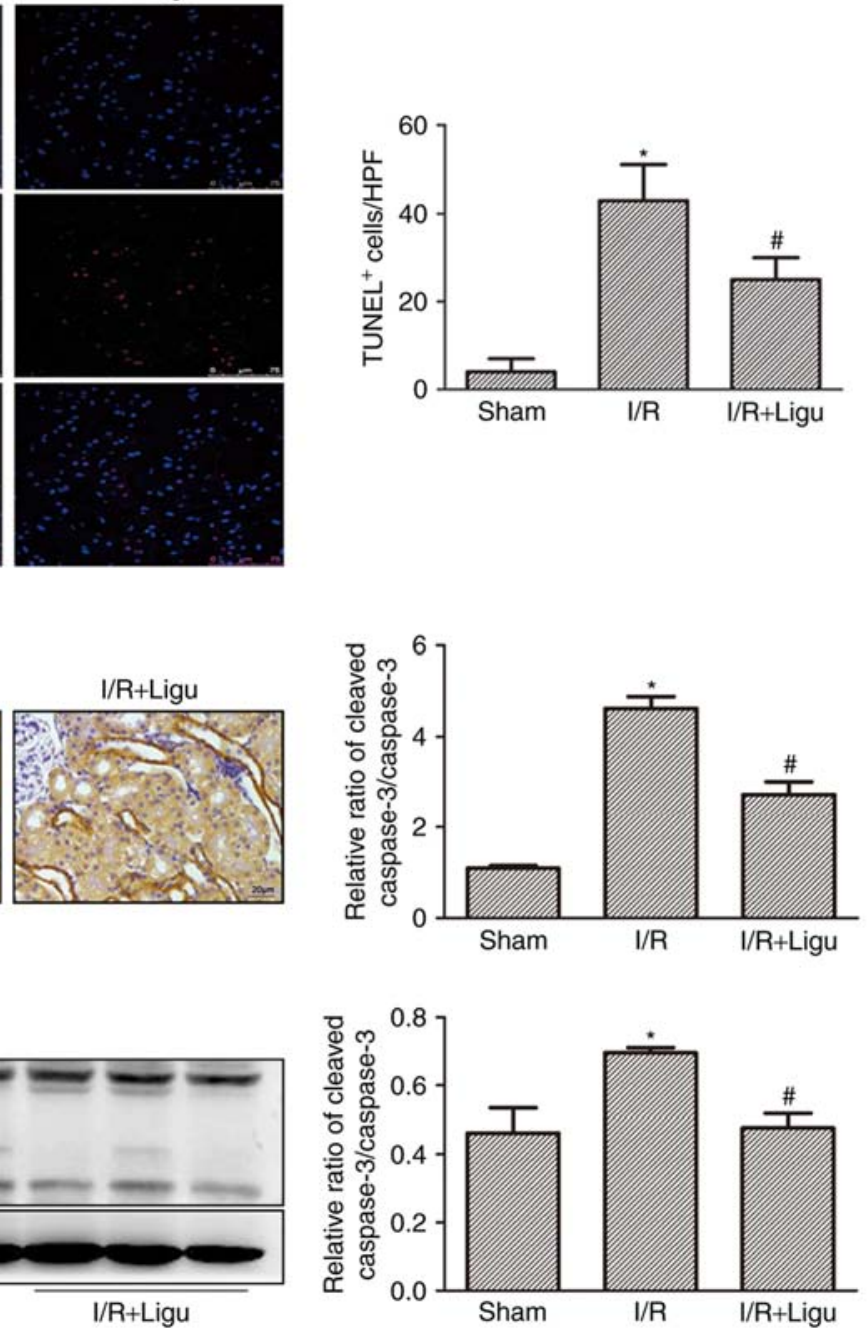

Figure 3. Ligustrazine inhibits kidney apoptosis after I/R. (A) TUNEL assays were performed to assess renal cell death. Nuclei were visualized using DAPI staining. Quantitative analysis of TUNEL+ cells (numbers per high-power field). Bars, $75 \mu \mathrm{m}$. (B) Representative photomicrographs of caspase $3 /$ cleaved caspase 3 immunohistochemical staining in kidneys from different groups. Bars, $20 \mu \mathrm{m}$ (magnification, $\mathrm{x} 400$ ). (C) Representative western blots and summarized data showing the levels of the ratio of caspase $3 /$ cleaved caspase 3 in kidneys from different groups. ${ }^{*} \mathrm{P}<0.05 \mathrm{vs}$. sham-operated rats $(\mathrm{n}=9)$, ${ }^{\#} \mathrm{P}<0.05 \mathrm{vs}$. $\mathrm{I} / \mathrm{R}$ rats $(\mathrm{n}=9)$. Ligu, ligustrazine; I/R, ischemia/reperfusion.

Western blot analysis revealed that ligustrazine at $50 \mu \mathrm{M}$ was able to significantly inhibit the upregulation of NOD2 expression induced by $\mathrm{CoCl}_{2}(500 \mu \mathrm{M})$ and OGD followed by reoxygenation for $24 \mathrm{~h}$ (Fig. $4 \mathrm{C}$ and $\mathrm{D}$ ).

Ligustrazine-mediated NOD2 downregulation is blocked by inhibiting autophagy in NRK-52E cells. Inflammation and autophagy are two inextricably linked and important pathophysiological processes. Since autophagy was previously shown to protect the proximal tubule from degeneration and acute ischemic injury (25), it was inferred that the anti-inflammatory effect of ligustrazine was mediated by autophagy. Consequently, this was tested in in vitro studies.

The differential autophagy response to $\mathrm{CoCl}_{2}$-induced hypoxia in rat NRK-52E cells was demonstrated by western blotting of LC3A/B-II/I. The ratio of LC3A/B-II/I increased after treatment with a lower concentration of $\mathrm{CoCl}_{2}$, indicating that this treatment could induce autophagy, whereas at a concentration of $500 \mu \mathrm{M} \mathrm{CoCl}$, the LC3A/B-II/I ratio was significantly decreased compared with that with 100 and $250 \mu \mathrm{M}$, indicating that the induction of autophagy was impaired with $\mathrm{CoCl}_{2}$ treatment at higher concentration (Fig. 5A). Moreover, the ratio of LC3A/B-II/I following $\mathrm{CoCl}_{2}$ treatment at a concentration of $500 \mu \mathrm{M}$ increased significantly with $50 \mu \mathrm{M}$ ligustrazine (Fig. 5B), suggesting that the impaired autophagy recovered following ligustrazine treatment.

Next, the association between the inhibition of inflammation and the induction of autophagy was addressed. Autophagy was inhibited with CQ. As an inhibitor of autophagy, CQ raises the lysosomal $\mathrm{pH}$ and ultimately inhibits the fusion between autophagosomes and lysosomes, thus preventing the maturation of autophagosomes into autolysosomes, and blocking a late step of macroautophagy. Thus, an increase in LC3-I and LC3-II is expected in the presence of CQ $(26,27)$. Following $\mathrm{CoCl}_{2}$ treatment $(500 \mu \mathrm{M})$, the inhibitory effect of ligustrazine on the protein levels of NOD2 was diminished when autophagy was inhibited, as determined by western blot analysis (Fig. 5C); moreover, western blot analysis demonstrated that, after OGD treatment followed by reoxygenation $(24 \mathrm{~h})$, the inhibitory 
A
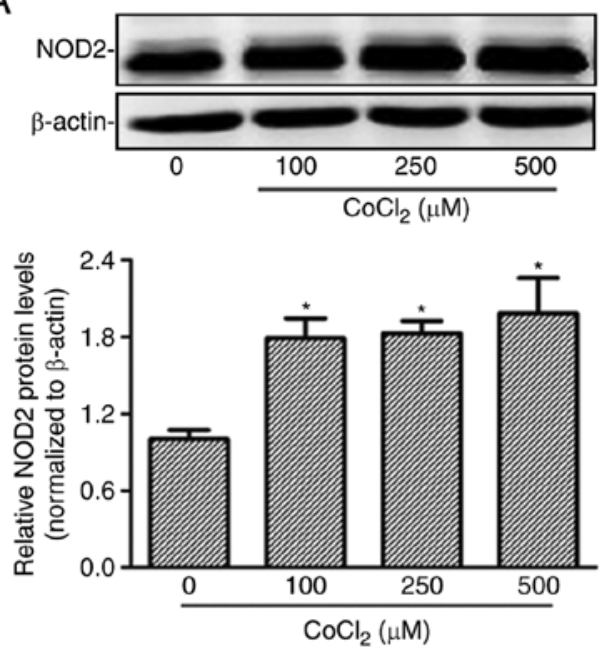

C

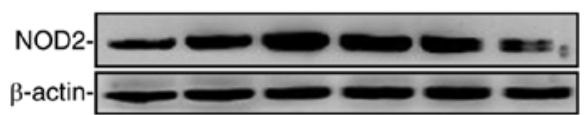

B
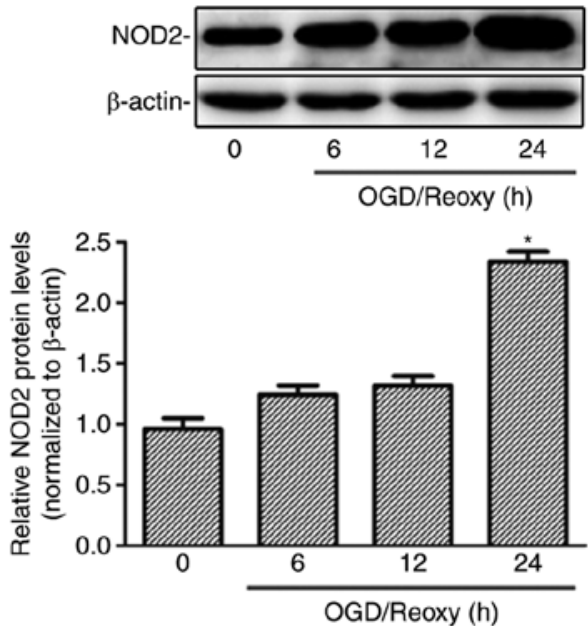

D
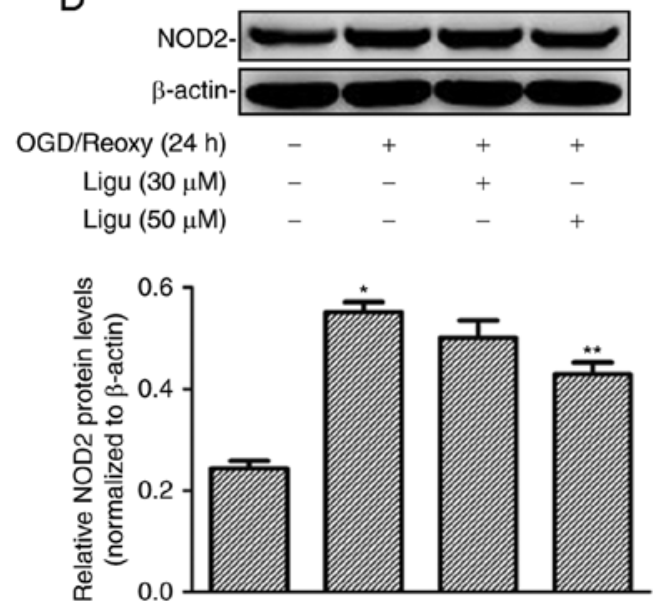

OGD/Reoxy $(24 \mathrm{~h})$

Ligu $(30 \mu \mathrm{M})$

Ligu $(50 \mu \mathrm{M})$

Figure 4. Ligustrazine inhibits NOD2 expression response to different hypoxia models in rat proximal tubule epithelial cells (NRK-52E cells). (A) Representative western blots and summarized data showing the protein levels of NOD2 in response to $\mathrm{CoCl}_{2}$ treatment at different concentrations. The treatment duration of $\mathrm{CoCl}_{2}$ was $12 \mathrm{~h}$. (B) Representative western blots and summarized data showing the protein levels of NOD2 in response to different recovery times following OGD. (C) Representative western blots and summarized data showing the protein levels of NOD2 in response to ligustrazine ( 30 and $50 \mu \mathrm{M}$ ) after $\mathrm{CoCl}_{2}$ treatment. (D) Representative western blots and summarized data showing the protein levels of NOD2 in response to ligustrazine (30 and $50 \mu \mathrm{M}$ ) after OGD treatment followed by reoxygenation $(24 \mathrm{~h})$. ${ }^{*} \mathrm{P}<0.05$ vs. control, ${ }^{\#} \mathrm{P}<0.05$ vs. $\mathrm{CoCl}_{2}$ treatment group (100 and $\left.250 \mu \mathrm{M}\right)$, ${ }^{*}, \mathrm{P}<0.05$ vs. ligustrazine treatment group $(30 \mu \mathrm{M}),{ }^{* *} \mathrm{P}<0.05$ vs. OGD treatment group. All the experiments were performed in triplicate. Ligu, ligustrazine; I/R, ischemia/reperfusion; NOD2, nucleotide-binding oligomerization domain containing 2; OGD, oxygen and glucose deprivation; reoxy, reoxygenation.

effect of ligustrazine on NOD2 levels was suppressed when autophagy was inhibited (Fig. 5D).

Ligustrazine-mediated downregulation of inflammation and apoptosis is blocked by inhibiting autophagy in NRK-52E cells in vitro. Furthermore, RT-qPCR analysis demonstrated that ligustrazine treatment inhibited the production of pro-inflammatory mediators, including TNF- $\alpha$, IL- 6 , and MCP-1, and this effect was blocked when autophagy was inhibited, after OGD treatment followed by reoxygenation for $12 \mathrm{~h}$ (Fig. 6A). These results suggest that the anti-inflammatory effect of ligustrazine depends to a certain extent on the induction of autophagy. CCK-8 assays demonstrated that cell viability in response to ligustrazine decreased after autophagy was inhibited by CQ (Fig. 6B). TUNEL assays were also performed to assess the effect of ligustrazine on cell death induced by $\mathrm{CoCl}_{2}$ treatment. Following inhibition of autophagy, the effect of ligustrazine on reducing cell death was attenuated (Fig. 6C).

\section{Discussion}

The present study demonstrated that ligustrazine downregulates autophagy-induced NOD2 expression, attenuates cell death and improves renal function following $\mathrm{I} / \mathrm{R}$ injury in a rat model. Furthermore, to the best of our knowledge, the present study was the first to identify that the inhibitory effect of ligustrazine on NOD2 depends on the induction of autophagy in NRK-52E cells treated with $\mathrm{CoCl}_{2}$ in vitro.

$\mathrm{I} / \mathrm{R}$ injury is a common clinical problem that has been attracting increasing attention in an attempt to delineate putative triggers of renal injury and design novel therapeutic 
A
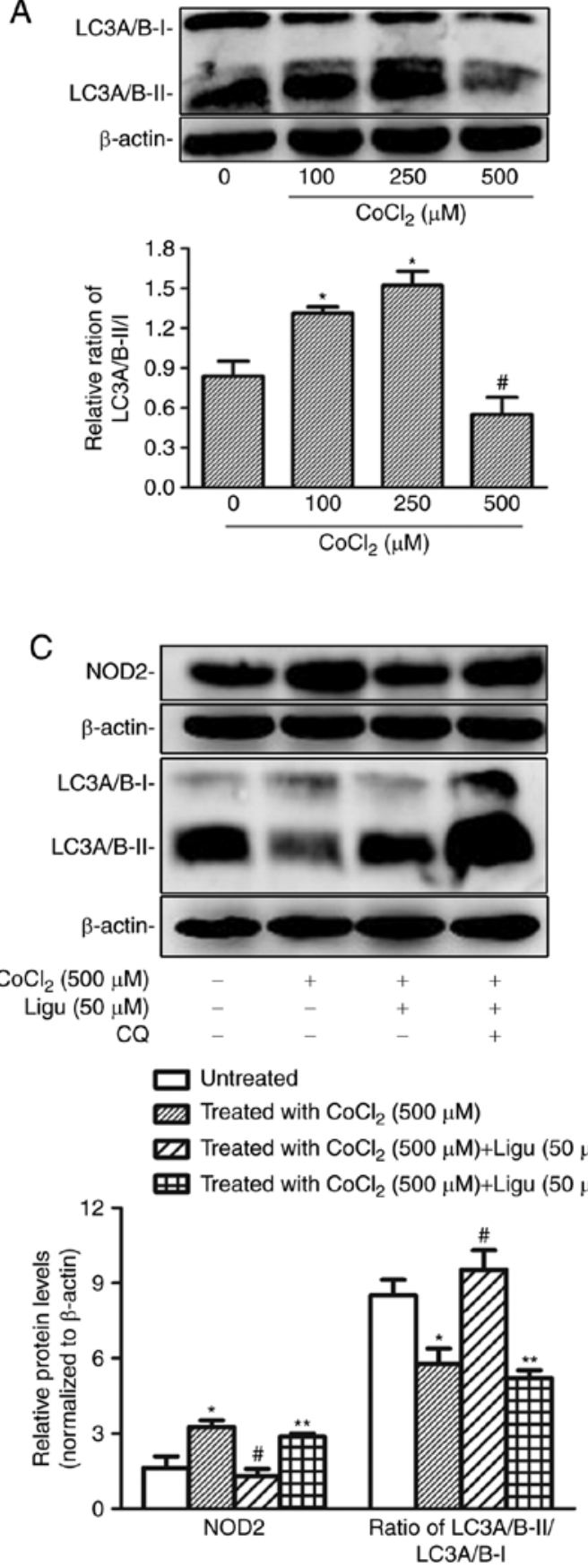
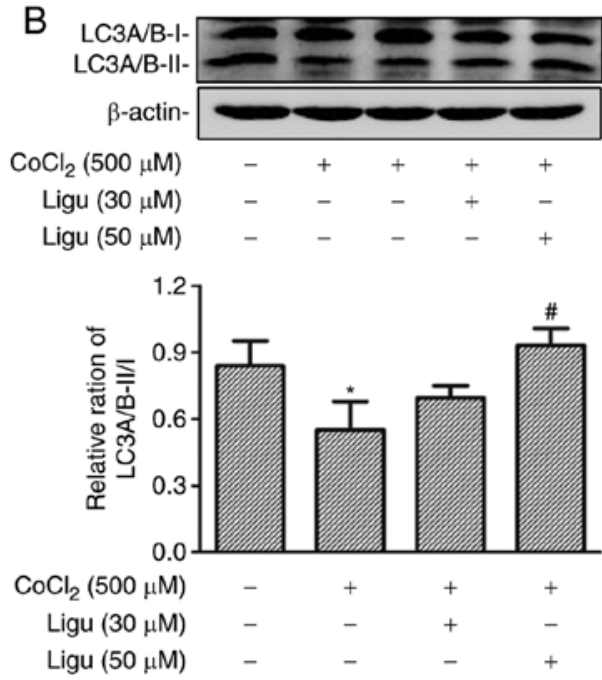

$\mathrm{D}$

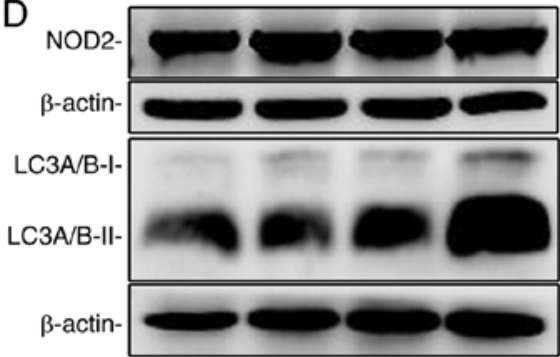

OGD/Reoxy (24 h)

Ligu $(50 \mu \mathrm{M})$

$\mathrm{CQ}$

Untreated

IIA Treated with OGD/Reoxy (24 h)

Z7 Treated with OGD/Reoxy (24 h)+Ligu $(50 \mu \mathrm{M})$

田 Treated with OGD/Reoxy $(24 \mathrm{~h})+$ Ligu $(50 \mu \mathrm{M})+\mathrm{CQ}$

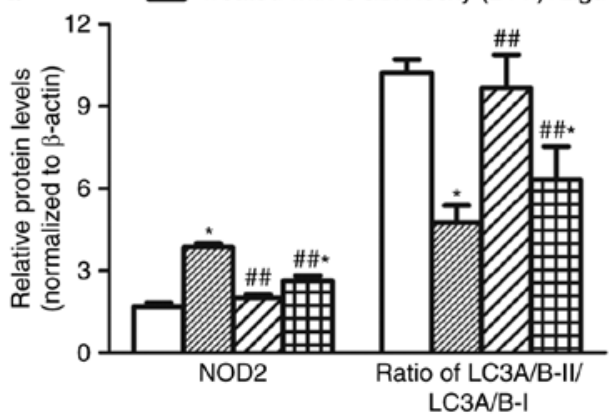

Figure 5. Ligustrazine-mediated NOD2 downregulation is blocked by inhibiting autophagy in NRK-52E cells in vitro. (A) Representative western blots and summarized data showing the relative ratio of $\mathrm{LC} 3 \mathrm{~A} / \mathrm{B}-\mathrm{II} / \mathrm{I}$ in response to $\mathrm{CoCl}_{2}$ treatment at different concentrations. The treatment duration of $\mathrm{CoCl}_{2}$ was $12 \mathrm{~h}$. (B) Representative western blots and summarized data showing the relative ratio of $\mathrm{LC} 3 \mathrm{~A} / \mathrm{B}$ - $\mathrm{II} / \mathrm{I}$ in response to ligustrazine (30 and $50 \mu \mathrm{M})$ after $\mathrm{CoCl}{ }_{2}$ treatment. The duration of $\mathrm{CoCl}_{2}$ treatment was $12 \mathrm{~h}$ and the duration of ligustrazine treatment was $24 \mathrm{~h}$. (C) Representative western blots and summarized data showing the protein levels of NOD2 in response to ligustrazine $(50 \mu \mathrm{M})$ after $\mathrm{CoCl}_{2}$ treatment when the autophagy was inhibited by CQ. (D) Representative western blots and summarized data showing the protein levels of NOD2 in response to ligustrazine after OGD treatment followed by reoxygenation (24 h) when the autophagy was inhibited by $\mathrm{CQ}$. ${ }^{*} \mathrm{P}<0.05$ vs. control, ${ }^{*} \mathrm{P}<0.05$ vs. $\mathrm{CoCl}_{2}$ treatment group, ${ }^{* *} \mathrm{P}<0.05$ vs. ligustrazine $(50 \mu \mathrm{M})$ after $\mathrm{CoCl}{ }_{2}$ treatment group, ${ }^{\# \#} \mathrm{P}<0.05$ vs. OGD treatment followed by reoxygenation $(24 \mathrm{~h})$ group. ${ }^{\# \#, *} \mathrm{P}<0.05$ vs. ligustrazine $(50 \mu \mathrm{M})$ after $\mathrm{OGD}$ treatment followed by reoxygenation ( $24 \mathrm{~h}$ ) group. All the experiments were performed in triplicate. Ligu, ligustrazine; I/R, ischemia/reperfusion; reoxy, reoxygenation; NOD2, nucleotide-binding oligomerization domain-containing 2; OGD, oxygen and glucose deprivation; CQ, chloroquine.

strategies. Ligustrazine is a natural small-molecule compound that was previously characterized and found to be associated with few side effects and favorable bioavailability in vivo (28), and determining its targets and mechanism of action may be beneficial for its clinical use. Recently, the anti-inflammatory role of ligustrazine was demonstrated in patients with rheumatic heart disease, a mouse model of allergic asthma and after spinal cord I/R injury in rats $(17,18,29)$, suggesting that these anti-inflammatory effects may underlie its renoprotective properties. The reduced level of pro-inflammatory mediators and infiltration of $\mathrm{CD}^{+} 8^{+}$macrophages in renal tissue by ligustrazine following I/R indicated that ligustrazine protects against AKI by suppressing inflammatory response. Furthermore, ligustrazine was found to suppress the expression 


\section{A}
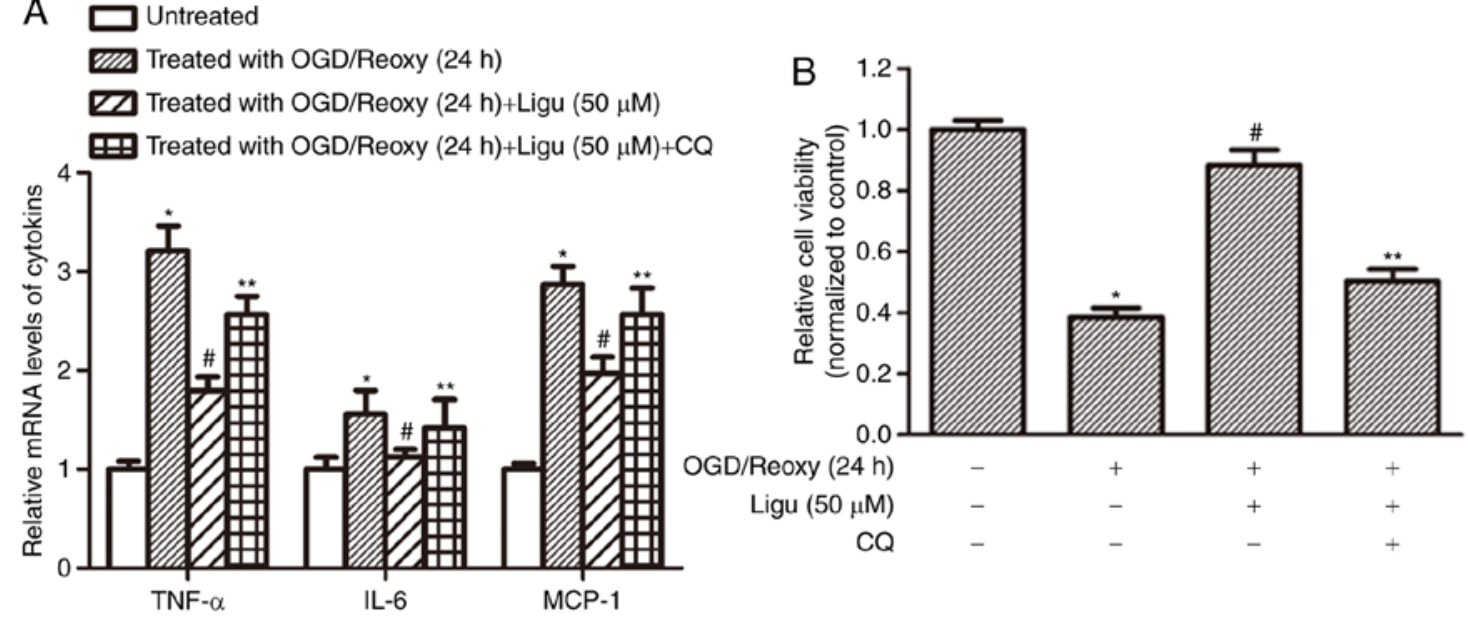

C
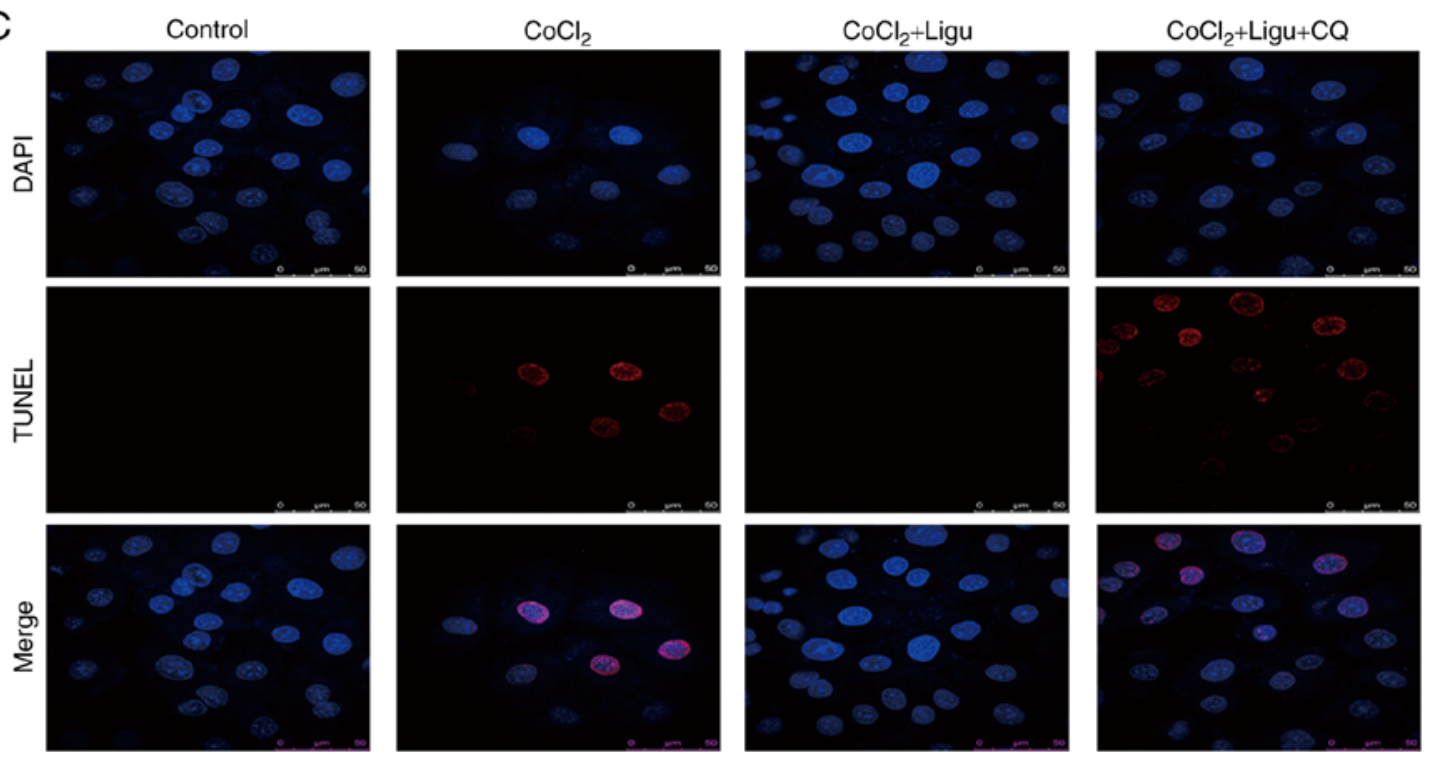

Figure 6. Ligustrazine-mediated downregulation of inflammation and apoptosis is blocked by inhibiting autophagy in NRK-52E cells in vitro. (A) RT-qPCR analysis demonstrated that ligustrazine treatment suppressed the levels of proinflammatory mediators, including TNF- $\alpha$, IL- 6 and MCP-1, and this effect was attenuated when autophagy was inhibited by CQ. The duration of reoxygenation was $24 \mathrm{~h}$. (B) CCK-8 assays demonstrated that cell viability in response to ligustrazine after OGD followed by reoxygenation for $24 \mathrm{~h}$ was blocked when the autophagy was inhibited by CQ. (C) TUNEL assays showing the changes of cell death in response to ligustrazine after $\mathrm{CoCl}_{2}$ treatment when autophagy was inhibited by CQ. The treatment duration of $\mathrm{CoCl}_{2}$ was $12 \mathrm{~h}$, and that of ligustrazine and $\mathrm{CQ}$ was $24 \mathrm{~h} .{ }^{*} \mathrm{P}<0.05$ vs. control, ${ }^{\prime} \mathrm{P}<0.05$ vs. OGD treatment, ${ }^{* *} \mathrm{P}<0.05$ vs. ligustrazine treatment group. All the experiments were performed in triplicate. Ligu, ligustrazine; I/R, ischemia/reperfusion; reoxy, reoxygenation; OGD, oxygen and glucose deprivation; CQ, chloroquine; TNF, tumor necrosis factor; IL, interleukin; MCP, monocyte chemoattractant protein.

of NOD2 and enhance autophagy in the injured kidney cortex following $\mathrm{I} / \mathrm{R}$ injury in rats.

PRRs have been suggested to be important triggers of ischemic injury $(30,31)$. NOD2 is a well-characterized member of the NLR family, which mediates the activation of $\mathrm{NF}-\mathrm{\kappa B}$ and mitogen-activated protein kinases in response to muramyl dipeptide, a peptidoglycan motif that is present in all gram-positive and gram-negative bacteria (32). The activation of NOD2 mainly leads to the production of pro-inflammatory cytokines and the expression of co-stimulatory and adhesion molecules, which are dependent on NF- $\mathrm{KB}$ activation (33). NOD2 was suggested to not only promote renal injury by exacerbating inflammation and podocyte insulin resistance during diabetic nephropathy, but also to participate in renal $\mathrm{I} / \mathrm{R}$, which is negatively regulated by progranulin, a protective autocrine growth factor involved in AKI $(11,13)$. In the present study, it was confirmed that the expression of NOD2 increases in the injured kidney cortex following renal I/R injury and in NRK-52E cells treated with $\mathrm{CoCl}_{2}$, a chemical reagent that promotes a cellular anaerobic state in vitro. Therefore, it was hypothesized that NOD2 may serve as a therapeutic target for AKI. The present study was the first to demonstrate that ligustrazine is associated with the innate immune response via NOD2.

To address the mechanism through which ligustrazine suppresses NOD2 expression, autophagy, an important physiological process that occurs during AKI, was investigated. In view of the current data, autophagy induction in response to multiple stresses induced by AKI is cytoprotective (34). In vitro, different levels of autophagy were demonstrated in NRK-52E cells treated with different concentrations of $\mathrm{CoCl}_{2}$. With a high concentration of $\mathrm{CoCl}_{2}$, the ratio of LC3A/B-II/I was significantly lower compared with that with low concentrations of $\mathrm{CoCl}_{2}$, suggesting that a high concentration of 
$\mathrm{CoCl}_{2}(500 \mu \mathrm{M})$ can cause serious cell damage through the induction of hypoxia and subsequent reoxygenation. Thus, autophagy was impaired to the extent that its protective effect against cell injury was lost. Therefore, a high concentration of $\mathrm{CoCl}_{2}$ was employed to test the effect of ligustrazine on the reactivation of autophagy. The results demonstrated that autophagy inhibition was significantly reversed by ligustrazine; in addition, the expression of NOD2 was also inhibited. We hypothesized that there is a functional association between NOD2 and autophagy. To confirm this hypothesis, autophagy was inhibited using an autophagy inhibitor, and the suppression of NOD2 by ligustrazine was partially abrogated. This indicated that the anti-inflammatory effect of ligustrazine depends on the induction of autophagy, at least to some extent. These results also provided more evidence supporting that NOD2 is a key mediator through which autophagy regulates the innate immune response and inflammation (35). Mammalian target of rapamycin (mTOR) is a key negative regulator of autophagy. Ligustrazine was previously shown to disrupt phosphoinositide 3-kinase/AKT/mTOR signaling in angiotensin II-activated hepatic stellate cells (36). Ligustrazine was also reported to prevent apoptosis by promoting autophagy in an AMP-activated protein kinase- and mTOR pathway-dependent manner in bone marrow mesenchymal stem cells (37).

Autophagy consists of an intracellular degradation system that is required for cellular homeostasis, and basal autophagy is important for proximal tubule homeostasis. Cellular stress during AKI, including hypoxia, oxidative injury and nutrient deprivation, contributes to the induction of autophagy. Conditional kidney proximal tubule-specific Atg5- or Atg7-knockout mice were used to demonstrate the renoprotective effect of autophagy following renal I/R injury $(25,38)$. However, the precise mechanisms underlying autophagy during AKI are unclear. In addition to the fact that the effect of ligustrazine on NOD2 downregulation was partially blocked by inhibiting autophagy, other studies also demonstrated the association of autophagy with NLRs in immune cells, which included the identification of cross-talk-related processes. The autophagy-related protein ATG16L1 was found to suppress inflammation selectively induced by the activation of NOD2 $(35,39,40)$, and autophagy was also found to play an important role as a macrophage-intrinsic negative regulator of the NLRP3 inflammasome $(32,33)$. Thus, the autophagic machinery comprises a key cellular monitoring system that prevents excessive NLRP3 inflammasome activation. Moreover, NOD2 and NLRP4 can regulate autophagic processes by associating with the autophagy-related protein Beclin 1 (41). However, the detailed underlying mechanisms remain elusive.

Hypoxia-induced tubular epithelial damage is prominent during renal $I / R$ injury, whereas post-reperfusion inflammation is a pathognomonic characteristic, involving multiple cell types and cell signals (8). Furthermore, glomerular injury and the excessive expression of adhesion molecules followed by leukocyte infiltration must be taken into consideration. A limitation of the present study was that the effect of ligustrazine on glomerular injury was not extensively addressed; in addition, whether ligustrazine regulates the association between NOD2 and autophagy in renal immune cells was not discerned. In the future, the effect of ligustrazine on the activation of NOD2 in glomerular cells such as podocytes, endothelial cells, or mesangial cells should be addressed. Another limitation was the intervention time for ligustrazine. In the pre-experiment, we constructed models of three time points, namely 24,48 and $72 \mathrm{~h}$, according to different reperfusion time. H\&E staining revealed that kidney injury in rats was the most severe at $24 \mathrm{~h}$ after I/R; $48 \mathrm{~h}$ later, the kidney injury in rats did not become worse, and gradually recovered with the prolongation of reperfusion time. This was in accordance with previous findings (42). Therefore, in terms of timing, we focused on $24 \mathrm{~h}$ after reperfusion. Pre-treatment with drugs prior to ischemia was previously found to promote renal function and attenuate inflammation after renal I/R injury (13). In the present study, we only investigated the effect of ligustrazine treatment after ischemia, whereas the effect of ligustrazine pre-treatment was not assessed. Additional studies must be conducted to explore the regulation of inflammation by autophagy following pre-treatment with ligustrazine.

Apoptosis is a major pathological process in AKI. There is cross-talk between autophagy and apoptosis in addition to inflammation $(34,43)$. In the present study, ligustrazine helped to preserve renal function in a model of $I / R$ injury in part by reducing apoptosis. In vitro, the effect of ligustrazine on inhibiting cell death was diminished after autophagy was suppressed. Thus, ligustrazine may be implicated in homeostasis and renal pathophysiology via an interaction between autophagy and apoptosis. Of note, although it was demonstrated that the inhibition of inflammation and apoptosis by ligustrazine partly depended on the induction of autophagy, other researchers have demonstrated that ligustrazine pre-treatment may reverse the increase in autophagy observed in an arsenic-induced nephrotoxicity cell model, which is considered to induce necrosis (44). These opposite results suggest that autophagy is a complex process, and its role in the protection against diseases requires comprehensive consideration. Thus, interfering with the regulation of inflammation by autophagy may be of great value in the treatment for kidney injury (45).

In conclusion, the present study was, to the best of our knowledge, the first to provide evidence that ligustrazine can protect against renal injury after AKI by suppressing NOD2-mediated inflammation, which is partly dependent on the induction of autophagy. Ligustrazine was investigated for its potential anti-inflammatory effects and its ability to induce autophagy, which may broaden its clinical application spectrum for immune- and autophagy-related diseases.

\section{Acknowledgements}

Not applicable.

\section{Funding}

The present study was supported by the National Natural Science Foundation of China (grant nos. 81500557 and 81601049); the Distinguished Middle-Aged and Young Scientist Encourage and Reward Foundation of Shandong Province (grant no. BS2014YY018); and the Natural Science Foundation of Shandong Province (grant nos. ZR2016HP05, ZR2016HL11 and ZR2017BH055). 


\section{Authors' contributions}

GJ, RX, WY and PD were responsible for study design, data collection, statistical analysis and manuscript preparation; LZ, WS, XM, HH, YH and LW were responsible for partial data collection, statistical analysis and literature search; PD supervised the entire project, study design, data analysis and writing of the manuscript. All authors have reviewed and approved the final manuscript.

\section{Availability of materials and data}

The data that support the findings of the present study are available from the corresponding author on reasonable request.

\section{Ethics approval and consent to participate}

The present study was approved by the Institutional Animal Care and Use Committee of Binzhou Medical University (protocol no. 2015-008).

\section{Patient consent for publication}

Not applicable.

\section{Competing interests}

All the authors declare that they have no competing interests.

\section{References}

1. Eltzschig HK and Eckle T: Ischemia and reperfusion-from mechanism to translation. Nat Med 17: 1391-1401, 2011

2. Rabb H, Griffin MD, McKay DB, Swaminathan S, Pickkers P, Rosner MH, Kellum JA and Ronco C; Acute Dialysis Quality Initiative Consensus XIII Work Group: Inflammation in AKI: Current understanding, key questions, and knowledge gaps. J Am Soc Nephrol 27: 371-379, 2016.

3. Shigeoka AA, Kambo A, Mathison JC, King AJ, Hall WF, da Silva Correia J, Ulevitch RJ and McKay DB: Nod1 and $\operatorname{nod} 2$ are expressed in human and murine renal tubular epithelial cells and participate in renal ischemia reperfusion injury. J Immunol 184: 2297-2304, 2010.

4. Bakker PJ, Butter LM, Claessen N, Teske GJ, Sutterwala FS, Florquin S and Leemans JC: A tissue-specific role for Nlrp3 in tubular epithelial repair after renal ischemia/reperfusion. Am J Pathol 184: 2013-2022, 2014.

5. Petrilli V, Dostert C, Muruve DA and Tschopp J: The inflammasome: A danger sensing complex triggering innate immunity. Curr Opin Immunol 19: 615-622, 2007.

6. Kersse K, Bertrand MJ,Lamkanfi M and Vandenabeele P: NOD-like receptors and the innate immune system: Coping with danger, damage and death. Cytokine Growth Factor Rev 22: 257-276, 2011.

7. Anders HJ and Lech M: NOD-like and Toll-like receptors or inflammasomes contribute to kidney disease in a canonical and a non-canonical manner. Kidney Int 84: 225-228, 2013.

8. Shigeoka AA, Mueller JL, Kambo A, Mathison JC, King AJ, Hall WF, Correia Jda S, Ulevitch RJ, Hoffman HM and McKay DB: An inflammasome-independent role for epithelial-expressed N1rp3 in renal ischemia-reperfusion injury. J Immunol 185: 6277-6285, 2010.

9. Szeto HH, Liu S, Soong Y, Seshan SV, Cohen-Gould L, Manichev V, Feldman LC and Gustafsson T: Mitochondria protection after acute ischemia prevents prolonged upregulation of IL-1 $\beta$ and IL-18 and arrests CKD. J Am Soc Nephrol 28: $1437-1449,2017$

10. Chun J, Chung H, Wang X, Barry R, Taheri ZM, Platnich JM, Ahmed SB, Trpkov K, Hemmelgarn B, Benediktsson $\mathrm{H}$, et al: NLRP3 localizes to the tubular epithelium in human kidney and correlates with outcome in IgA nephropathy. Sci Rep 6: 24667, 2016.
11. Du P, Fan B, Han H, Zhen J, Shang J, Wang X, Li X, Shi W, Tang W, Bao C, et al: NOD2 promotes renal injury by exacerbating inflammation and podocyte insulin resistance in diabetic nephropathy. Kidney Int 84: 265-276, 2013.

12. Xin R, Sun X, Wang Z, Yuan W, Jiang W, Wang L, Xiang Y, Zhang H, Li X, Hou Y, et al: Apocynin inhibited NLRP3/XIAP signalling to alleviate renal fibrotic injury in rat diabetic nephropathy. Biomed Pharmacothe 106: 1325-1331, 2018.

13. Zhou M, Tang W, Fu Y, Xu X, Wang Z, Lu Y, Liu F, Yang X, Wei X, Zhang Y, et al: Progranulin protects against renal ischemia/reperfusion injury in mice. Kidney Int 87: 918-929, 2015.

14. Wang GJ: The change in the nailfold microcirculation in patients with acute cerebral thrombosis treated with ligustrazine. Zhonghua Shen Jing Jing Shen Ke Za Zhi 17: 121-124, 1984 (In Chinese).

15. Pang PK, Shan JJ and Chiu KW: Tetramethylpyrazine, a calcium antagonist. Planta Med 62: 431-435, 1996.

16. Zhang Z, Wei T, Hou J,Li G, Yu S and Xin W: Tetramethylpyrazine scavenges superoxide anion and decreases nitric oxide production in human polymorphonuclear leukocytes. Life Sci 72: 2465-2472, 2003

17. Chen YJ, Huang CS, Wang F, Gong JY and Pan ZH: Effect of ligustrazine hydrochloride on coagulation reaction and inflammation reaction in single valve replacement patients with rheumatic heart disease undergoing cardiopulmonary bypass. Zhongguo Zhong Xi Yi Jie He Za Zhi 34: 531-535, 2014 (In Chinese).

18. Luo YC, Xiang QW and Wang Q: Effect of ligustrazine on expression of RhoA mRNA, ROCK-II protein in the lung and airway inflammation of allergic asthma model mice. Zhonghua Er Ke Za Zhi 46: 868-869, 2008 (In Chinese).

19. Fan LP, Shen JZ, Fu HY, Zhou HR, Shen SF and Yu AF: Effect of epigallocatechin-3-galate on human acute monocytic leukemia cell line U937 and its relevant mechanism. Zhongguo Shi Yan Xue Ye Xue Za Zhi 18: 286-290, 2010 (In Chinese).

20. Bai XY, Wang XF, Zhang LS, Du PC, Cao Z and Hou Y: Tetramethylpyrazine ameliorates experimental autoimmune encephalomyelitis by modulating the inflammatory response. Biochem Biophys Res Commun 503: 1968-1972, 2018.

21. Tan Z: Neural protection by naturopathic compounds-an example of tetramethylpyrazine from retina to brain. J Ocul Biol Dis Infor 2: 57-64, 2009.

22. Chen S, Xiong L, Wang Q, Sang H, Zhu Z, Dong H and Lu Z: Tetramethylpyrazine attenuates spinal cord ischemic injury due to aortic cross-clamping in rabbits. BMC Neurol 2: 1,2002.

23. AVMA Guidelines for the Euthanasia of Animals: 2013 edition. https://www.avma.org/sites/default/files/resources/euthanasia.pdf

24. Livak KJ and Schmittgen TD: Analysis of relative gene expression data using real-time quantitative PCR and the 2(-Delta Delta C(T)) Method. Methods 25: 402-408, 2001.

25. Kimura T, Takabatake Y, Takahashi A, Kaimori JY, Matsui I, Namba T, Kitamura H, Niimura F, Matsusaka T, Soga T, et al: Autophagy protects the proximal tubule from degeneration and acute ischemic injury. J Am Soc Nephrol 22: 902-913, 2011.

26. Fedorko M: Effect of chloroquine on morphology of cytoplasmic granules in maturing human leukocytes-an ultrastructural study. J Clin Invest 46: 1932-1942, 1967.

27. Klionsky DJ, Abdelmohsen K, Abe A, Abedin MJ, Abeliovich H, Acevedo Arozena A, Adachi H, Adams CM, Adams PD, Adeli K, et al: Guidelines for the use and interpretation of assays for monitoring autophagy (3rd edition). Autophagy 12: 1-222, 2016.

28. Shen T, Xu H, Weng W and Zhang J: Single- and multiple-dose pharmacokinetics of a novel tetramethylpyrazine reservoir-type transdermal patch versus tetramethylpyrazine phosphate oral tablets in healthy normal volunteers, and in vitro/in vivo correlation. Biol Pharm Bull 36: 931-937, 2013.

29. Fan L, Wang K, Shi Z, Die J, Wang C and Dang X: Tetramethylpyrazine protects spinal cord and reduces inflammation in a rat model of spinal cord ischemia-reperfusion injury. J Vasc Surg 54: 192-200, 2011.

30. Goncalves GM, Castoldi A, Braga TT and Camara NO: New roles for innate immune response in acute and chronic kidney injuries. Scand J Immunol 73: 428-435, 2011.

31. Wang X and Yi F: Implication of pattern-recognition receptors in cardiovascular diseases. Antioxid Redox Signal 22: 1130-1145, 2015.

32. Inohara N, Ogura Y, Fontalba A, Gutierrez O, Pons F, Crespo J, Fukase K, Inamura S, Kusumoto S, Hashimoto M, et al: Host recognition of bacterial muramyl dipeptide mediated through NOD2. Implications for Crohn's disease. J Biol Chem 278: 5509-5512, 2003 . 
33. Lipinski S, Till A, Sina C, Arlt A, Grasberger H, Schreiber S and Rosenstiel P: DUOX2-derived reactive oxygen species are effectors of NOD2-mediated antibacterial responses. J Cell Sci 122. 3522-3530, 2009.

34. Kaushal GP and Shah SV: Autophagy in acute kidney injury. Kidney Int 89: 779-791, 2016.

35. Plantinga TS, Crisan TO, Oosting M, van de Veerdonk FL, de Jong DJ, Philpott DJ, van der Meer JW, Girardin SE, Joosten LA and Netea MG: Crohn's disease-associated ATG16L1 polymorphism modulates pro-inflammatory cytokine responses selectively upon activation of NOD2. Gut 60: 1229-1235, 2011.

36. Zhang X, Zhang F, Kong D, Wu X, Lian N, Chen L, Lu Y and Zheng S: Tetramethylpyrazine inhibits angiotensin II-induced activation of hepatic stellate cells associated with interference of platelet-derived growth factor $\beta$ receptor pathways. FEBS J 281: 2754-2768, 2014.

37. Wang L, Zhang HY, Gao B, Shi J, Huang Q, Han YH, Hu YQ, Lu WG, Zhao ZJ, Liu BH, et al: Tetramethylpyrazine protects against glucocorticoid-induced apoptosis by promoting autophagy in mesenchymal stem cells and improves bone mass in glucocorticoid-induced osteoporosis rats. Stem Cells Dev 26: 419-430, 2017.

38. Jiang M, Liu K, Luo J and Dong Z: Autophagy is a renoprotective mechanism during in vitro hypoxia and in vivo ischemia-reperfusion injury. Am J Pathol 176: 1181-1192, 2010.

39. Sorbara MT, Ellison LK, Ramjeet M, Travassos LH, Jones NL, Girardin SE and Philpott DJ: The protein ATG16L1 suppresses inflammatory cytokines induced by the intracellular sensors Nod1 and Nod2 in an autophagy-independent manner. Immunity 39: 858-873, 2013.
40. Saitoh T, Fujita N, Jang MH, Uematsu S, Yang BG, Satoh T, Omori H, Noda T, Yamamoto N, Komatsu M, et al: Loss of the autophagy protein Atg16L1 enhances endotoxin-induced IL-1beta production. Nature 456: 264-268, 2008.

41. Jounai N, Kobiyama K, Shiina M, Ogata K, Ishii KJ and Takeshita F: NLRP4 negatively regulates autophagic processes through an association with beclin1. J Immunol 186: 1646-1655, 2011.

42. Pulskens WP, Teske GJ, Butter LM, Roelofs JJ, van der Poll T, Florquin $\mathrm{S}$ and Leemans JC: Toll-like receptor- 4 coordinates the innate immune response of the kidney to renal ischemia/reperfusion injury. PLoS One 3: e3569, 2008.

43. Yang C, Kaushal V, Shah SV and Kaushal GP: Autophagy is associated with apoptosis in cisplatin injury to renal tubular epithelial cells. Am J Physiol Renal Physiol 294: F777-F787, 2008.

44. Gong X, Ivanov VN, Davidson MM and Hei TK: Tetramethylpyrazine (TMP) protects against sodium arsenite-induced nephrotoxicity by suppressing ROS production, mitochondrial dysfunction, pro-inflammatory signaling pathways and programed cell death. Arch Toxicol 89: 1057-1070, 2015.

45. Kimura T, Isaka Y and Yoshimori T: Autophagy and kidney inflammation. Autophagy 13: 997-1003, 2017.

(i) () This work is licensed under a Creative Commons

EY NO ND Attribution-NonCommercial-NoDerivatives 4.0 International (CC BY-NC-ND 4.0) License. 